Article

\title{
Design and Verification of Humidity Sensors Based on Magnesium Oxide Micro-Arc Oxidation Film Layers
}

\author{
Mingqiang Pan 1,2,3, Jun Sheng 1,2,3,*, Jizhu Liu 1,2,3,*, Zeming Shi 1,2,3 and Lei Jiu 1,2,3 \\ 1 School of Mechanical and Electric Engineering, Soochow University, Suzhou 215123, China; \\ pmqw1@126.com (M.P.); 20195229044@stu.suda.edu.cn (Z.S.); 20175229049@stu.suda.edu.cn (L.J.) \\ 2 Jiangsu Provincial Key Labor Atory of Advanced Robotics, Soochow University, Suzhou 215123, China \\ 3 Robotics and Microsystems Center, Soochow University, Suzhou 215123, China \\ * Correspondence: 20185229013@stu.suda.edu.cn (J.S.); liu_jizhu@163.com (J.L.)
}

Received: 23 December 2019; Accepted: 16 March 2020; Published: 20 March 2020

\begin{abstract}
Humidity detection range is an important indicator for measuring the performance of humidity sensors, but semiconductor humidity sensors often face the problems of narrow detection ranges and insufficient detection sensitivities. In this paper, a magnesium oxide (MgO) humidity sensor based on micro-arc oxidation (MAO) technology was designed to solve these problems by simultaneously using impedance and capacitance as the response signals, as well as by normalizing the output of the two signals. The experimental results showed that the average output of the micro-arc $\mathrm{MgO}$ ceramic film, with impedance as the response signal, could reach 150 in the low relative humidity $(\mathrm{RH})$ range $(11.3-67 \% \mathrm{RH})$, which was much higher than its sensitivity in the high humidity range $(<1)$, and the film showed fast response (13 s) and recovery (61 s). Under high humidity conditions (67-97.3\% RH), with capacitance as the response signal, the output of the micro-arc $\mathrm{MgO}$ was as high as 120 . Therefore, the micro-arc MgO humidity sensor with impedance, and the sensor with capacitance as the response signal, demonstrated good stability in low humidity and in high humidity environments, respectively, indicating that the method of selecting appropriate response signals for different humidity environments can be applied to extend the humidity detection range of sensing material, and to improve the humidity detection capability of a sensor.
\end{abstract}

Keywords: humidity range; $\mathrm{MgO}$; micro-arc oxidation; response signal

\section{Introduction}

Humidity sensors have been widely used in various fields of human production and life, including weather forecasting, health care, and food processing [1-6]. Relative humidity (RH) detection range is an important indicator to measure the detection performance of humidity sensors. It is often utilized differently in different fields. Many humidity sensors currently exhibit distinct moisture sensitivity responses in different humidity environments. Yin et al. [7] designed a 3D pillared-layer cadmium (II) metal organic framework, the impedance change of which was greater than two orders of magnitude in the range of $54-97 \%$ RH. However, no significant change in impedance was found in the low humidity range, indicating it was only suitable for medium and high humidity environment testing. Juhász et al. [8] used an anodic oxidation technique to prepare a porous alumina humidity sensor with sensitivity up to $27 \mathrm{pF} / \mathrm{RH} \%$ in the high humidity range, and merely $2.5 \mathrm{pF} / \mathrm{RH} \%$ in the low humidity range. The development of a humidity sensor with a wide range of detection capability has become a research hotspot. At present, most researchers focus on the modification of materials and microstructure [9-12]. Few paid attention to the influence of the choice of response signals on the performance of humidity sensors [13-15]. 
Micro-arc oxidation (MAO) is a new technology to directly grow ceramic layers in situ on the surface of non-ferrous metals. This is done by placing a valve metal (such as $\mathrm{Al}, \mathrm{Mg}$, $\mathrm{Ti}$, or their alloys) in an aqueous electrolyte solution, and using electrochemical methods to generate spark discharge points in the surface micropores of the material, which is a method for generating oxides under the influence of thermochemistry, plasma chemistry, and electrochemistry. Technologies like this have the advantages of easy operation, environmental protection, and high efficiency $[16,17]$. Meanwhile, $\mathrm{MgO}$ as a transition metal oxide is rarely used as a sensing material, and the main reason is that it has a larger band gap, which makes it more difficult to generate carriers. However, its faster carrier mobility gives it more potential to develop a humidity sensor with a rapid response $[18,19]$.

To this end, this paper is devoted to the use of MAO to grow MgO film layers in situ on the surface of $\mathrm{Mg}$ plates to produce humidity sensing material. The microstructure and composition of the oxide layer were characterized by scanning electron microscopy (SEM) and energy dispersive $\mathrm{X}$-ray spectroscopy (EDS). The phase composition of the oxide layer was analyzed by X-ray diffraction (XRD). At the same time, impedance and capacitance were selected as the response signals to detect the humidity sensing performance of the film layer. The experimental results showed that the micro-arc $\mathrm{MgO}$ film with a porous structure on the surface had a large specific surface area. In different humidity environments, the micro-arc $\mathrm{MgO}$ film layer with impedance and capacitance as the response signals showed a major difference in output, indicating that the method of selecting appropriate response signals for different humidity conditions could be used to extend the humidity detection range of sensing material.

\section{Materials and Methods}

\subsection{Materials Synthesis}

The specific manufacturing steps (as shown in Figure 1) of the sensor were as following:

(a) First, a $20 \times 20 \times 5 \mathrm{~mm}$ magnesium plate sample was cut out (purity $>99.5 \%$ ). Sandpaper (400 \# $\rightarrow 600$ \# $\rightarrow 800$ \#) was used to grind and remove oil ( $10 \% \mathrm{NaOH}$ solution), then the magnesium plate was rinsed with deionized water and air-dried for later use.

(b) $\mathrm{A} 10 \mathrm{~g} / \mathrm{L} \mathrm{Na} 2 \mathrm{SiO}_{3}$ solution using deionized water was prepared, and then $\mathrm{NaOH}$ powder was added to adjust the $\mathrm{pH}$ of the electrolyte to 13 .

(c) The sample was hung on the electrode and immersed into the electrolyte. The anode was a magnesium plate and the cathode was a stainless steel electrolytic cell.

(d) The power supply parameters were adjusted. The average current density was $4 \mathrm{~A} / \mathrm{cm} 2$, the duty cycle was $35 \%$, the frequency was $550 \mathrm{~Hz}$, the temperature of the electrolyte was maintained at $10-40^{\circ} \mathrm{C}$, and the oxidation time was $20 \mathrm{~min}$. A circulating cooling device was used to keep the temperature of the configured electrolyte at $10-40^{\circ} \mathrm{C}$.

(e) After oxidation, the micro-arc $\mathrm{MgO}$ plate was rinsed thoroughly with deionized water and dried in hot air.

(f) A 200 \# interdigital electrode screen plate was designed and purchased. The test piece was placed under the mesh, and the prepared conductive silver paste was uniformly printed on the micro-arc oxidation plate through the screen hole by using a scraper.

(g) After the printing was completed, the MAO plate was held at $80^{\circ} \mathrm{C}$ for $1 \mathrm{~h}$ to ensure that the silver paste was completely cured to fabricate a micro-arc $\mathrm{MgO}$ humidity sensor. 


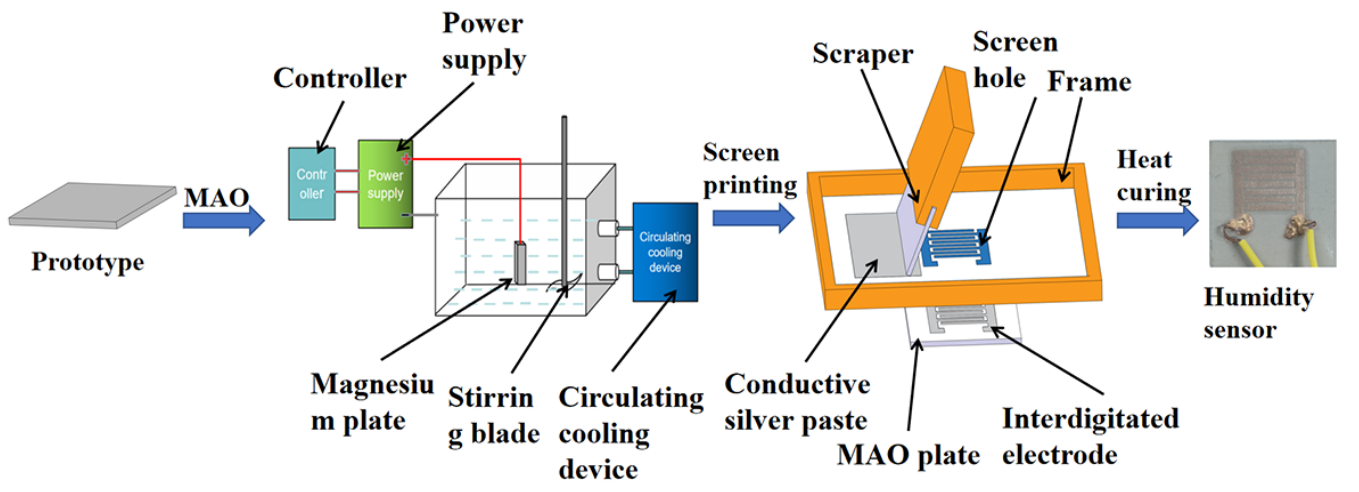

Figure 1. Micro-arc MgO humidity sensor fabrication process.

\subsection{Fabrication of Humidity Sensor}

As shown in Figure 2, the glass chamber was double-layered, and the inter layer was filled with plastic foam as a moisture barrier. The humidity in the glass chamber was controlled by the evaporation of water. The glass chamber had a built-in thermo-hygrograph as an indicator of ambient temperature and humidity. The entire unit could stably obtain a humidity range of $20-80 \% \mathrm{RH}$. The signal electrode and signal receiving device (Agilent 33210A, 34410A) (Agilent, Suzhou, China) of the fabricated micro-arc $\mathrm{MgO}$ humidity sensor were connected with a computer. An AC voltage of $5 \mathrm{~V}$ was applied to obtain the impedance characteristics thereof.

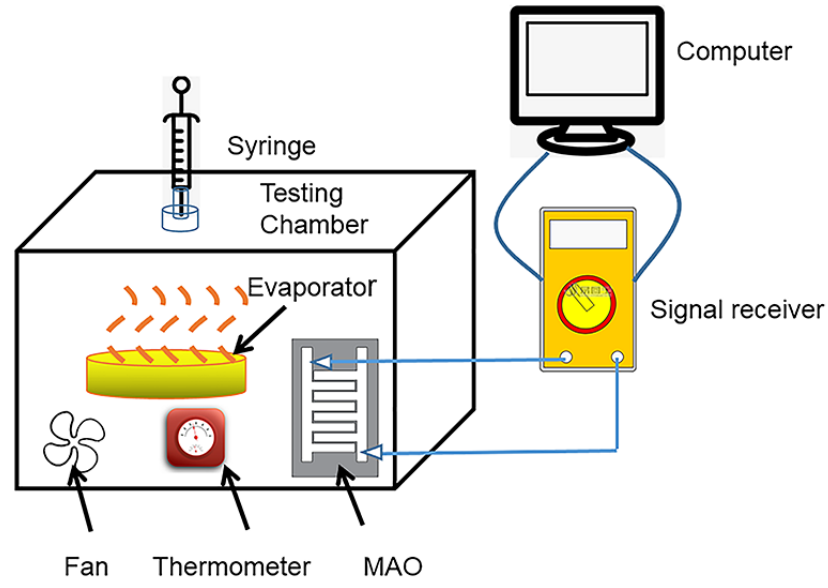

Figure 2. Schematic diagram of experimental setup for testing humidity sensors.

Capacitance testing was performed using an LCR bridge tester (VC4090A) (Victor, Suzhou, China) at an operating frequency of $1 \mathrm{kHz}$. The entire device could continuously change the humidity in the test environment, which was mainly used to test the change in the two response signals (impedance and capacitance) of the sensor with humidity.

In addition, this paper configured $\mathrm{LiCl}(11.3 \% \mathrm{RH}), \mathrm{CH}_{3} \mathrm{COOK}(22.5 \% \mathrm{RH}), \mathrm{MgCl}_{2}(32.8 \% \mathrm{RH})$, $\mathrm{K}_{2} \mathrm{CO}_{3}(43.2 \% \mathrm{RH}), \mathrm{NaBr}(57.6 \% \mathrm{RH}), \mathrm{NaCl}(75.3 \% \mathrm{RH}), \mathrm{KCl}(84.2 \% \mathrm{RH})$, and $\mathrm{K}_{2} \mathrm{SO}_{4}(97.3 \% \mathrm{RH})$ of $25{ }^{\circ} \mathrm{C}$ saturated solution in order to obtain a stable humidity environment [20]. This particular solution was mainly used to test the response time and recovery time, wet hysteresis, and stability of sensors.

\section{Results and Discussion}

\subsection{Characterization Results}

The surface morphology and microstructure of the micro-arc $\mathrm{MgO}$ film layer were characterized by SEM, as shown in Figure 3a-c. 

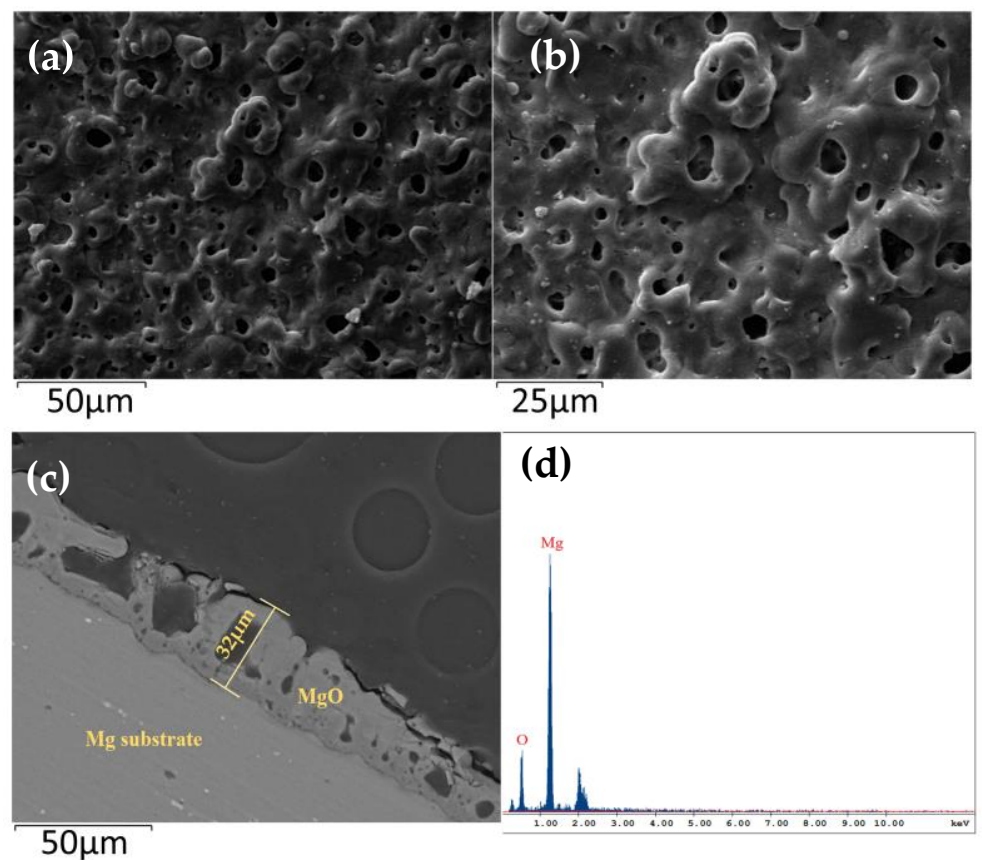

Figure 3. SEM images of micro-arc $\mathrm{MgO}$ film layer surface (a) low magnification and (b) high magnification; (c) section image of micro-arc $\mathrm{MgO}$; (d) EDS image of micro-arc $\mathrm{MgO}$.

The surface and cross section of the micro-arc $\mathrm{MgO}$ film layer were shown at different magnifications. The thickness of the micro-arc oxide film was about $32 \mu \mathrm{m}$, which had good continuity, while the surface had a large number of abnormal pores with a diameter of $4-8 \mu \mathrm{m}$. This microporous structure allowed the micro-arc $\mathrm{MgO}$ film layer to have a larger surface area, providing more adsorption sites and reaction channels for water molecules, which was helpful for enhancing the moisture-sensing properties of the material. Figure $3 \mathrm{~d}$ is an EDS diagram of the film layer, showing that the main components are $\mathrm{Mg}$ and $\mathrm{O}$ elements.

The XRD measurement of the micro-arc MgO film layer was performed with an X-ray diffractometer. The XRD results (Figure 4) showed that the MAO coating was mainly composed of $\mathrm{MgO}$ and $\mathrm{Mg}$, where $\mathrm{MgO}$ was the reaction product in the MAO process and the main phase in the MAO coating.

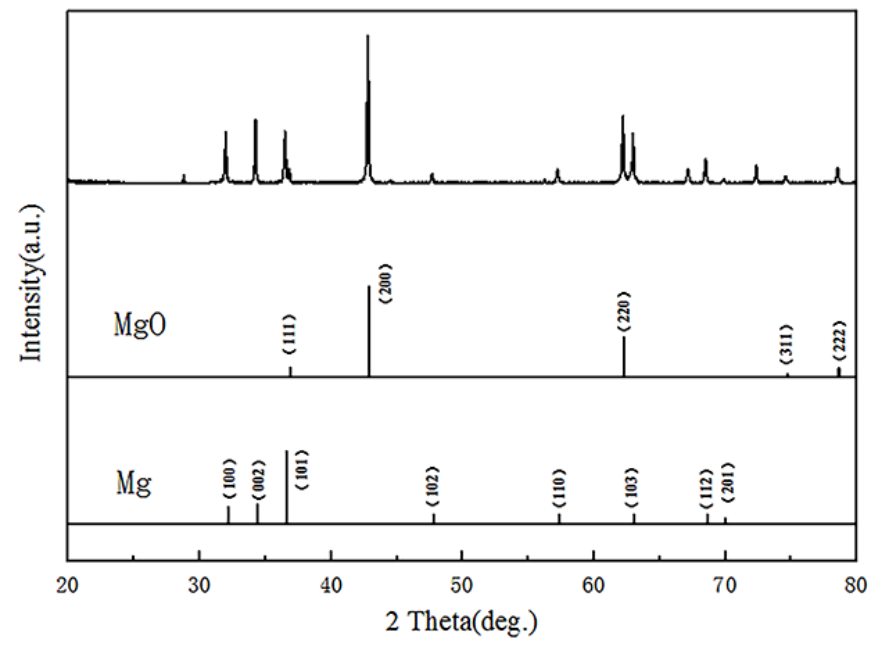

Figure 4. XRD image of micro-arc MgO film. 


\subsection{Humidity-Sensing Properties}

Figure 5 a shows the relationship between different frequency conditions with the impedance of micro-arc $\mathrm{MgO}$ as a function of humidity, and it can be seen that at each frequency, the impedance of the micro-arc $\mathrm{MgO}$ decreases with the increase of humidity. However, as the frequency increased, the magnitude of this change decreased more significantly. Considering that micro-arc $\mathrm{MgO}$ with low frequency tests had higher sensitivity, excessively low frequency was expected to increase the complexity of signal conditioning. At the same time, excessive impedance at low frequencies required complex amplification circuits and rigorous application test conditions, resulting in low practicality. Therefore, the operating frequency of $1 \mathrm{kHz}$ was selected to measure the humidity-sensing performance of the micro-arc $\mathrm{MgO}$. Figure 5b shows that the micro-arc $\mathrm{MgO}$ humidity sensor exhibited good stability at the operating frequency of $1 \mathrm{kHz}$. Especially under high humidity conditions, there were no significant fluctuations in the impedance measured for multiple times.

At the $1 \mathrm{kHz}$ operating frequency, the impedance and capacitance of the film in different humidity environments were measured separately to investigate the effects of different response signals on the humidity sensing performance of micro-arc MgO. As shown in Figure 6a, when $\mathrm{RH}$ rose from 11.3\% to $97.3 \%$, the impedance was used as the detection signal. In the low humidity environment, the impedance of the micro-arc $\mathrm{MgO}$ decreased exponentially with the increase in humidity. However, as the humidity continued to increase, the rate of decrease in the impedance of the film was significantly reduced, and finally there was no significant change. When the capacitor was used as the response signal, the capacitance rose slowly in the low humidity environment. As the humidity continued to increase, the film capacitance rose significantly and eventually increased exponentially. In order to find out the best switching point between the two signals, the signal outputs of the sensor were standardized and expressed by $S_{R}$ and $S_{C}$ :

$$
\begin{aligned}
& S_{\mathrm{R}}=\frac{\mathrm{R}_{\mathrm{RH}}-\mathrm{R}_{97.3 \% R H}}{\mathrm{R}_{97.3 \% \mathrm{RH}}} \\
& \mathrm{S}_{\mathrm{C}}=\frac{\mathrm{C}_{\mathrm{RH}}-\mathrm{C}_{11.3 \% \mathrm{RH}}}{\mathrm{C}_{11.3 \% \mathrm{RH}}}
\end{aligned}
$$

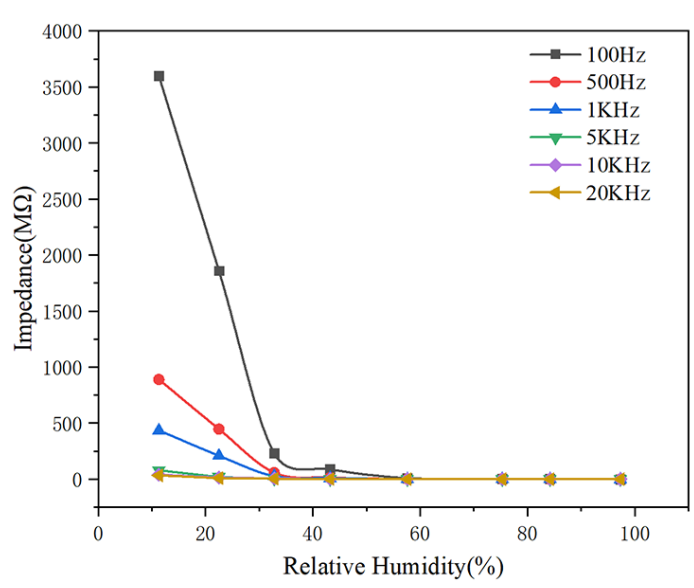

(a)

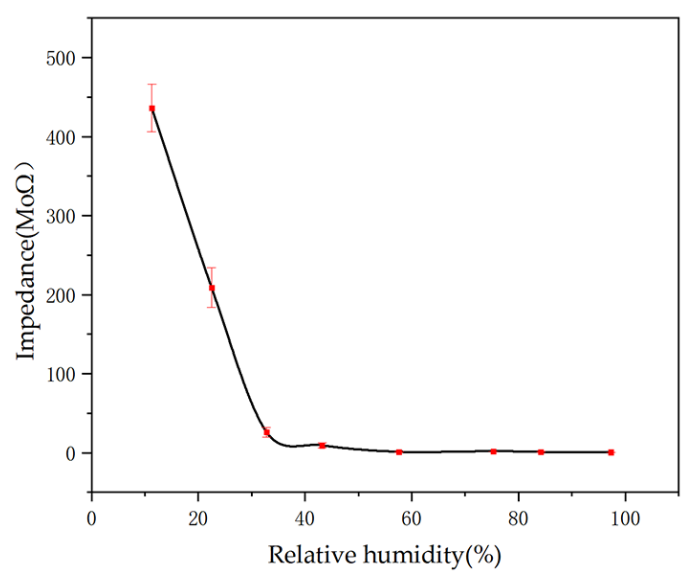

(b)

Figure 5. (a) Effect of humidity on the impedance of micro-arc $\mathrm{MgO}$ at different frequencies; (b) $1 \mathrm{kHz}$ error graph. 


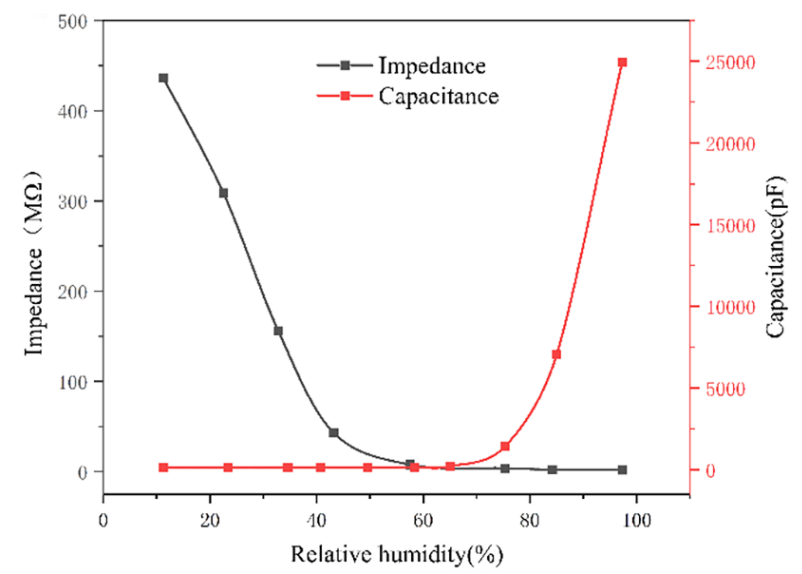

(a)

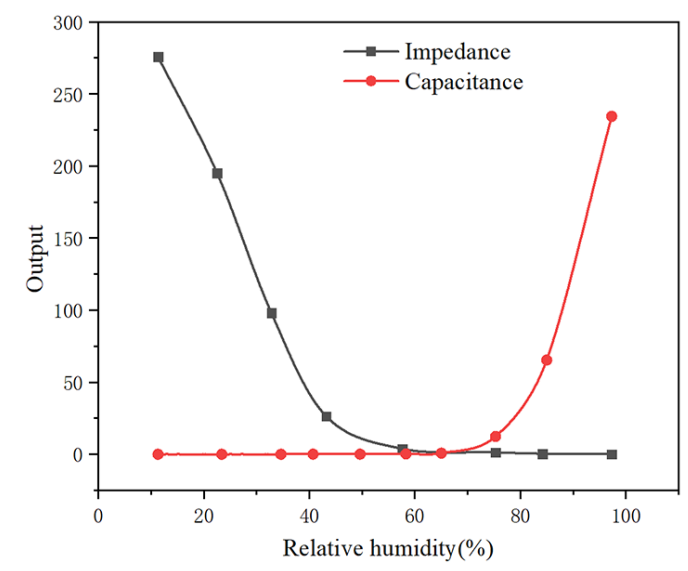

(b)

Figure 6. Micro-arc MgO humidity sensor (a) impedance and capacitance versus relative humidity; (b) output versus relative humidity.

$\mathrm{S}_{\mathrm{R}}$ and $\mathrm{S}_{\mathrm{C}}$ denote the output result of micro-arc $\mathrm{MgO}$ when impedance and capacitance are used as response signals. $\mathrm{R}_{\mathrm{RH}}$ and $\mathrm{C}_{\mathrm{RH}}$ are the impedance and capacitance of micro-arc $\mathrm{MgO}$ in various humidity environments, respectively. $\mathrm{R}_{97.3 \%}$ and $\mathrm{C}_{11.3 \%}$ represent the impedance and capacitance values of the micro-arc $\mathrm{MgO}$ at $97.3 \% \mathrm{RH}$ and $11.3 \% \mathrm{RH}$, respectively.

Figure $6 \mathrm{~b}$ shows the output curve of micro-arc $\mathrm{MgO}$ with two kinds of response signals used. The intersection point of the curves is point $\mathrm{A}$, and the corresponding humidity is about $67 \%$. It can be seen that at relative humidity of $11.3-67 \%$, when the response signal of the micro-arc $\mathrm{MgO}$ humidity sensor was impedance, the average output result could reach 150 . On the contrary, at a relative humidity of $67-97.3 \%$, the average output of a micro-arc $\mathrm{MgO}$ humidity sensor with capacitance as the response signal was about 120, which was much higher than the output of micro-arc $\mathrm{MgO}$ using impedance as the response signal $(<1)$. Obviously, when the impedance was used as the response signal, the micro-arc $\mathrm{MgO}$ had a high response in a low humidity environment. The micro-arc $\mathrm{MgO}$ humidity sensor with capacitance as the detection signal was more suitable for application under high humidity conditions. The relative humidity in the two response signals' output change led to turning points at $67 \%$. Designing a condition circuit to switch the response signal of the $\mathrm{MgO}$ film is key to the practical application of the above ideas. At present, there are related studies on this part. For example, Xin et al. [21] designed a signal switching circuit to switch signals through multi-channel gated switches. Realized real-time display and switching of measurement signals and observation signals. The above shows that it is feasible to improve the detection performance of the humidity sensor by means of signal switching.

Figure 7a,b demonstrates the response and recovery characteristics of micro-arc MgO. Relevant parameters were measured in a humidity bottle filled with a saturated solution. The environmental change from $11 \% \mathrm{RH}$ to $75 \% \mathrm{RH}$ was mainly achieved by rapidly transferring the micro-arc $\mathrm{MgO}$ plate along the route of $\mathrm{LiCl}(11.3 \% \mathrm{RH}) \rightarrow \mathrm{NaCl}(75.3 \% \mathrm{RH}) \rightarrow \mathrm{LiCl}(11.3 \% \mathrm{RH})$, thereby achieving the measurement of response time and recovery time. The response time and recovery time of the micro-arc $\mathrm{MgO}$ humidity sensor with impedance and capacitance as the response signal were 13 and 67 , and 341 and $61 \mathrm{~s}$, respectively. At the same time, this paper compared the response time and recovery time of other reported humidity sensors (see Table 1), which could prove that when the impedance was used as the response signal, the micro-arc $\mathrm{MgO}$ humidity sensor had faster response and recovery. However, the response time and recovery time of some excellent commercial humidity sensors could be controlled within 10s. Therefore, the response time and recovery time of the micro-arc $\mathrm{MgO}$ humidity sensor need to be further optimized. 
Table 1. Response and recovery time of several moisture-sensitive materials.

\begin{tabular}{|c|c|c|c|c|c|}
\hline Type & Meas Range & $\begin{array}{c}\text { Inductive } \\
\text { Signal Type }\end{array}$ & $\begin{array}{l}\text { Response } \\
\text { Time (s) }\end{array}$ & $\begin{array}{c}\text { Recovery Time } \\
\text { (s) }\end{array}$ & Ref \\
\hline \multirow{2}{*}{ MAO MgO } & \multirow{2}{*}{$11-75.3 \% \mathrm{RH}$} & Impedance & 13 & 61 & \multirow{2}{*}{ This work } \\
\hline & & Capacitance & 341 & 63 & \\
\hline $\mathrm{MoSe}_{2} / \mathrm{CuWO}_{4}$ & $0-67 \%$ RH & Capacitance & 109 & 9 & [22] \\
\hline $\mathrm{ZnO} / \mathrm{MoS}_{2}$ & $0-85 \%$ RH & Current & 138 & 166 & [23] \\
\hline $\mathrm{PbBi}_{2} \mathrm{Se}_{4}$ & $11-97 \%$ RH & Resistance & 65 & 75 & [24] \\
\hline NFC/CNT & $11-95 \% \mathrm{RH}$ & Current & 330 & 377 & [25] \\
\hline Polyimide & 25-90\%RH & Capacitance & 20 & 22 & [26] \\
\hline
\end{tabular}

Figure $7 \mathrm{c}, \mathrm{d}$ show the hysteresis of the two sensors when the humidity rises from $11.3 \% \mathrm{RH}$ to $97.3 \% \mathrm{RH}$ and then drops to $11.3 \% \mathrm{RH}$. The micro-arc $\mathrm{MgO}$ humidity sensor with impedance as the response signal has a hysteresis of about $3.8 \%$ at $47 \% \mathrm{RH}$. When the capacitance is used as the response signal, the hysteresis calculated by the sensor at $78 \% \mathrm{RH}$ is about $5.7 \%$. Further, we compared the hysteresis of the designed humidity sensor with other types of humidity sensors (as shown in Table 2). It can be seen that the micro-arc $\mathrm{MgO}$ humidity sensor has low hysteresis.

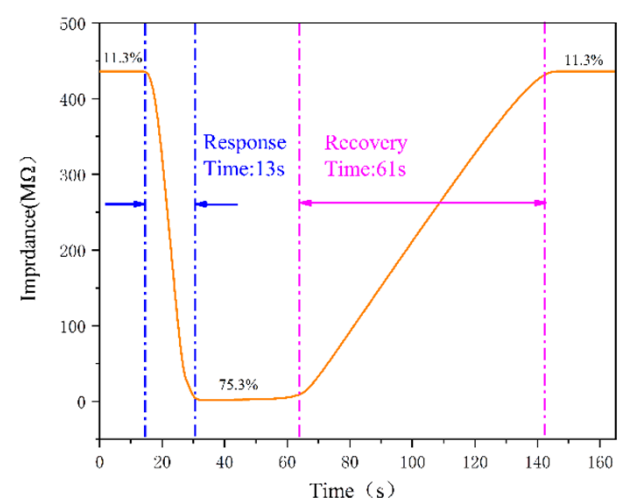

(a)

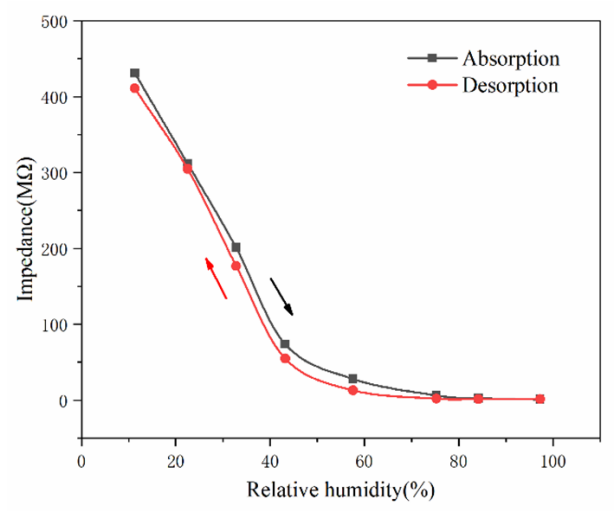

(c)

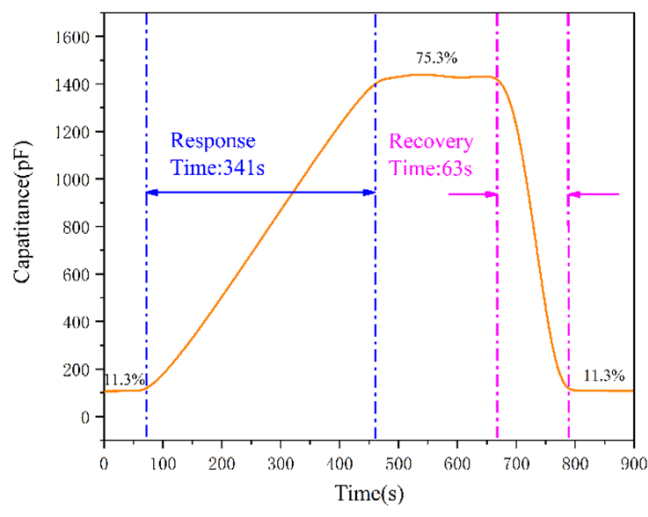

(b)

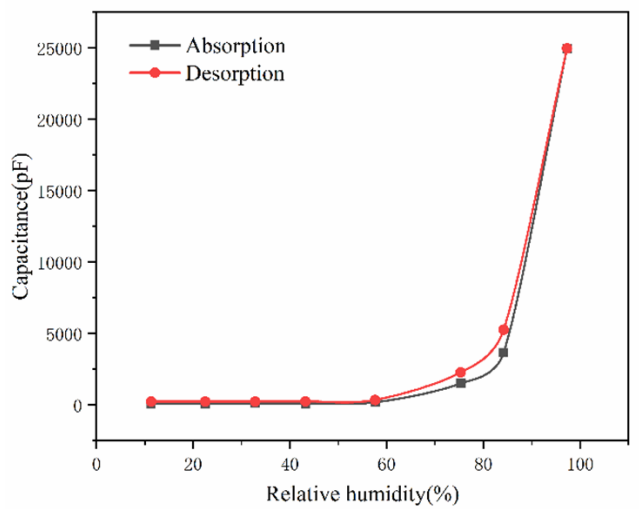

(d)

Figure 7. (a) Response/recovery time and (c) hysteresis characteristics of micro-arc MgO humidity sensor with impedance as response signal; (b) response/recovery time and (d) hysteresis characteristics of the micro-arc $\mathrm{MgO}$ humidity sensor with capacitance as a response signal. 
Figure $8 \mathrm{a}, \mathrm{b}$ represent the exponential fitting of the response curves of the two humidity sensors, respectively. The response signals of the two sensors are used as a function of relative humidity, and their functional expressions are expressed. The coefficient of determination $R^{2}$ is 0.9724 and 0.9977 , respectively, indicating a good curve fitting. Figure $8 \mathrm{c}$,d show that the two humidity sensors have good stability in the low humidity $(11.3 \%, 32.8 \%$, and $57.6 \%)$ and in the high humidity $(57.6 \%, 75.3 \%$ and $97.3 \%$ ) environments, respectively.

Table 2. Comparison of hysteresis effects of several moisture-sensitive materials.

\begin{tabular}{|c|c|c|c|c|}
\hline Type & Maximum Hysteresis (\%) & $\begin{array}{l}\text { Inductive } \\
\text { Signal Type }\end{array}$ & $\begin{array}{l}\text { Relative Humidity } \\
\text { (\% RH) }\end{array}$ & Ref \\
\hline \multirow{2}{*}{$\mathrm{MAO} \mathrm{MgO}$} & 3.8 & Impedance & 13 & \multirow{2}{*}{ This work } \\
\hline & 5.7 & Capacitance & 341 & \\
\hline $\mathrm{SnO}_{2} / \mathrm{MoS}_{2}$ & 5.5 & Capacitance & 67 & [27] \\
\hline $\mathrm{TiO}_{2} /$ graphene & 6.02 & Resistance & 48 & [28] \\
\hline $\mathrm{Au}-\mathrm{ZnO}$ & 2.35 & Impedance & 75 & [29] \\
\hline Polyaniline-holmium & 1.2 & Resistance & 55 & [30] \\
\hline Gr-AgNps & 6 & \multirow{2}{*}{ Capacitance } & 80 & \multirow{2}{*}{ [31] } \\
\hline Gr-AgNps-PMMA & 9 & & 75 & \\
\hline
\end{tabular}

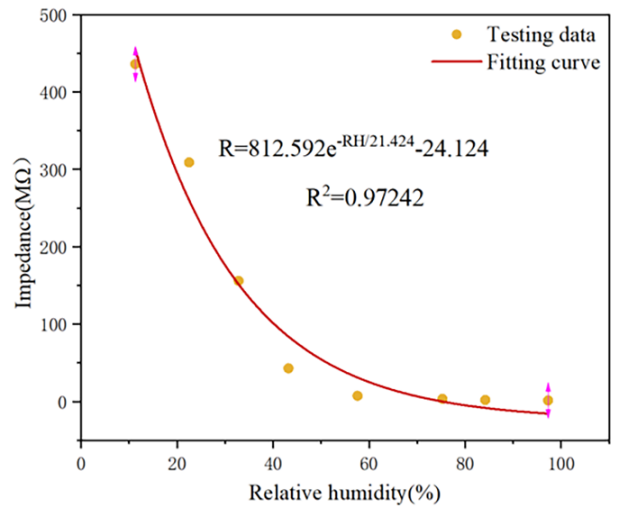

(a)

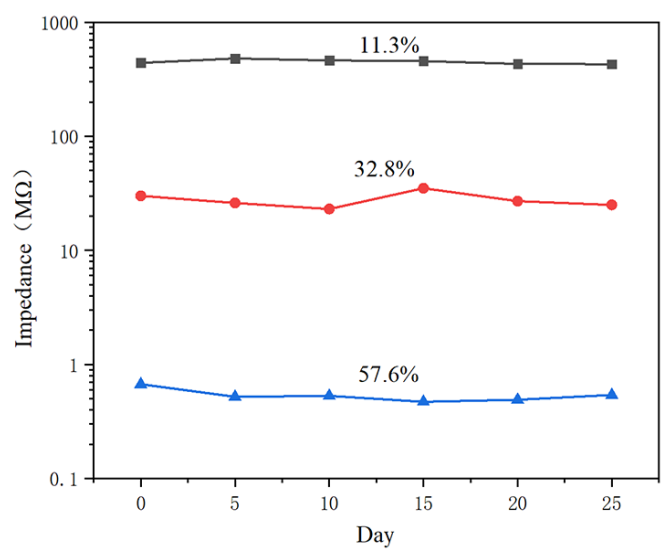

(c)

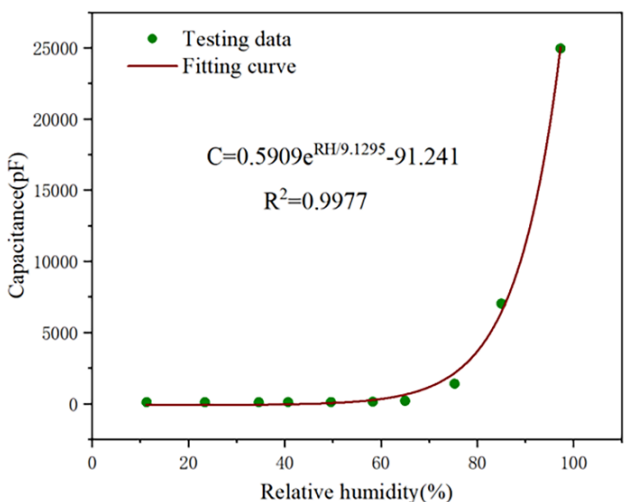

(b)

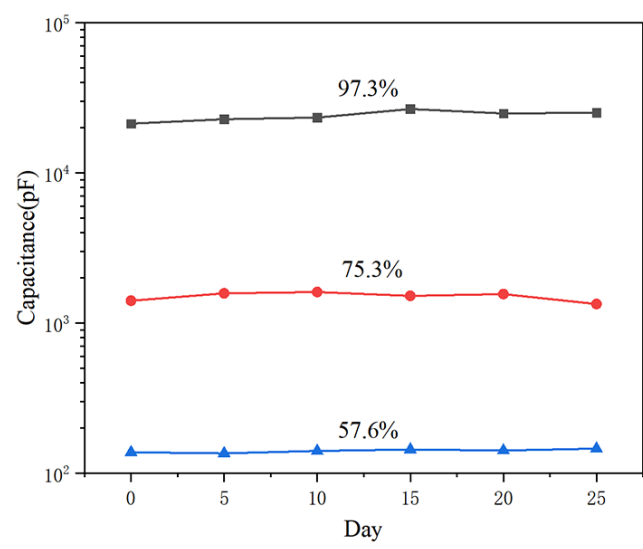

(d)

Figure 8. Sensor response as a function of RH in the range of $11.3-96.3 \% \mathrm{RH}$ for the (a) impedance and (b) capacitance as micro-arc $\mathrm{MgO}$ humidity sensor response signal, the (c) impedance and (d) capacitance are used as the response signals of the micro-arc $\mathrm{MgO}$ humidity sensor, with good stability in low humidity and high humidity environments respectively. 
Table 3 compares the humidity detection performance of the micro-arc MgO moisture-sensitive film layer with other sensing materials. It can be seen that various humidity sensors exhibit different humidity detection capabilities in different humidity environments. In general, the impedance is more suitable as a detection signal under low humidity conditions, and the capacitance is more suitable as a detection signal under high humidity conditions. Compared with other moisture-sensitive materials, the micro-arc $\mathrm{MgO}$ film layer has more obvious sensitivity difference in high-humidity and low humidity environments.

Table 3. Comparison in sensing properties towards various humidity sensors.

\begin{tabular}{|c|c|c|c|c|c|}
\hline \multirow{2}{*}{ Type } & \multicolumn{2}{|c|}{ Sensitivity } & \multirow{2}{*}{$\begin{array}{l}\text { Inductive } \\
\text { Signal Type }\end{array}$} & \multirow{2}{*}{ Meas. Range } & \multirow{2}{*}{ Ref } \\
\hline & $11-57 \%$ RH & $57-90 \% \mathrm{RH}$ & & & \\
\hline \multirow{2}{*}{ MAO MgO } & $0.5 \mathrm{pF} / \% \mathrm{RH}$ & $800 \mathrm{pF} / \% \mathrm{RH}$ & Capacitance & \multirow{2}{*}{$11.3-97.3 \% \mathrm{RH}$} & \multirow{2}{*}{ This work } \\
\hline & $9 \mathrm{M} \Omega / \% \mathrm{RH}$ & $33 \mathrm{k} \Omega / \% \mathrm{RH}$ & Impedance & & \\
\hline \multirow{2}{*}{$\mathrm{AAO} \mathrm{Al}_{2} \mathrm{O}_{3}$} & $0.05 \mathrm{pF} / \% \mathrm{RH}$ & $0.3 \mathrm{pF} / \% \mathrm{RH}$ & Capacitance & \multirow{2}{*}{$20-90 \%$ RH } & \multirow{2}{*}{ [15] } \\
\hline & $3.125 \mathrm{M} \Omega / \% \mathrm{RH}$ & $6.67 \mathrm{M} \Omega / \% \mathrm{RH}$ & Resistance & & \\
\hline Si-NPA & $3.8 \mathrm{k} \Omega / \% \mathrm{RH}$ & $0.65 \mathrm{k} \Omega / \% \mathrm{RH}$ & Resistance & $11.3-94.6 \%$ RH & [32] \\
\hline $\mathrm{SnO}_{2} / \mathrm{MoS}_{2}$ & $333 \mathrm{pF} / \% \mathrm{RH}$ & $4600 \mathrm{pF} / \% \mathrm{RH}$ & Capacitance & 0-90\% RH & [27] \\
\hline $\mathrm{AAO} \mathrm{Al}_{2} \mathrm{O}_{3}$ & $80 \mathrm{pF} / \% \mathrm{RH}$ & $333 \mathrm{pF} / \% \mathrm{RH}$ & Capacitance & $10-90 \% \mathrm{RH}$ & {$[33]$} \\
\hline $\mathrm{CuFe}_{2} \mathrm{O}_{4}-\mathrm{Y}_{2} \mathrm{O}_{3}$ & $8 \mathrm{M} \Omega / \% \mathrm{RH}$ & $1 \mathrm{M} \Omega / \% \mathrm{RH}$ & Resistance & $11.3-97.3 \% \mathrm{RH}$ & [34] \\
\hline
\end{tabular}

\subsection{Humidity Sensing Mechanism Analysis}

\subsubsection{Sensing Mechanism of Micro-Arc MgO with Impedance as the Response Signal}

$\mathrm{MgO}$ is a p-type semiconductor, which has a larger band gap (7.8 eV) than other metal oxides. Since the surface positive ions $\left(\mathrm{Mg}^{2+}\right)$ had greater electron affinity than the internal positive ions, the surface acceptor level occurred slightly below the conduction band bottom [35]. The negative ion $\left(0^{2-}\right)$ on the surface had greater electron repellency than the internal negative ion, so the surface donor level appeared slightly above the valence band. Before the adsorption of water molecules by micro-arc $\mathrm{MgO}$, the density of surface states of donors was significantly higher than that of acceptor surface states, which led to the downward bending of the energy band at the surface, forming a hole depletion layer, and exhibiting high impedance [36]. The surface of the micro-arc MgO ceramic material was in contact with water molecules, where the electrons did not need to cross the valence band, thus the water molecules could directly source electrons from the semiconductor valence band. One end of the hydrogen atom was attracted by $\mathrm{O}^{2-}$ on the surface of the material, which caused the density of the surface donor state to decrease. The originally trapped holes were released, while the carrier concentration rose, showing a decrease in resistance [37]. At the same time, compared with other metal oxides, $\mathrm{MgO}$ had faster carrier mobility $[19,35]$, which made the film impedance decrease rapidly with increasing humidity at the low relative humidity, showing rapid response. However, with the increase of humidity, it had been confirmed that the thickness of the water film was as high as several tens of water molecules in the case of high humidity, and when the physically adsorbed water molecules could not continue to form an additional donor (acceptor) state, that is, in a high humidity environment, the impedance of the micro-arc $\mathrm{MgO}$ did not continue to change significantly with the increase of the relative humidity [38]. 


\subsubsection{Sensing Mechanism of Micro-Arc MgO with Capacitance as the Response Signal}

As shown in Figure 9, the capacitance of the sensor is related to the proton conductivity [19]. Firstly, $\mathrm{H}_{2} \mathrm{O}$ was ionized to form hydroxyl $\left(\mathrm{OH}^{-}\right)$and hydrogen $\left(\mathrm{H}^{+}\right)[39]$ :

$$
\mathrm{H}_{2} \mathrm{O} \Leftrightarrow \mathrm{H}^{+}+\mathrm{OH}^{-}
$$

$\mathrm{OH}^{-}$was chemically adsorbed on the surface of the membrane and was connected to the metal cation $\left(\mathrm{Mg}^{2+}\right)$ by hydrogen bonding, so that the chemically adsorbed aqueous layer was firmly bonded to the surface of the sensing membrane, which was difficult to remove. In a low humidity environment, discontinuous water molecules were mainly physically adsorbed above the chemisorbed layer to form a first physically adsorbed aqueous layer. However, because hydrogen bonding limited the free movement of water molecules, protons did not have a continuous jump path, thus at this stage, the capacitance increased slowly with increasing RH. As RH continued to increase to higher levels, multiple continuous water molecules appeared on the surface of the membrane layer, which made the transfer of hydronium ions $\left(\mathrm{H}_{3} \mathrm{O}^{+}\right)$easier than before. According to the Grotthuss chain reaction [40,41], this process was under an electrostatic field where proton hopping occurred and proton conductivity was significantly improved:

$$
\begin{gathered}
2 \mathrm{H}_{2} \mathrm{O} \rightarrow \mathrm{H}_{3} \mathrm{O}^{+}+\mathrm{OH}^{-} \\
\mathrm{H}_{3} \mathrm{O}^{+}+\mathrm{H}_{2} \mathrm{O} \rightarrow \mathrm{H}_{2} \mathrm{O}+\mathrm{H}_{3} \mathrm{O}^{+}
\end{gathered}
$$

Physically adsorbed water molecules would penetrate into the pores of the membrane layer, further improving the sensor response. All of these factors caused a sudden increase in capacitance, so there was a large slope in the relationship between capacitance and RH. Meanwhile, according to this mechanism, three adsorbing steps, including the generation of first chemisorbed layer, first physisorbed layer, and multi-physisorbed layer, exist in adsorption process. Each process will continuously increase the capacitance of the sensor. Compared to a resistive humidity sensor, the response time of a micro-arc $\mathrm{MgO}$ humidity sensor with a capacitance as a response signal is longer.

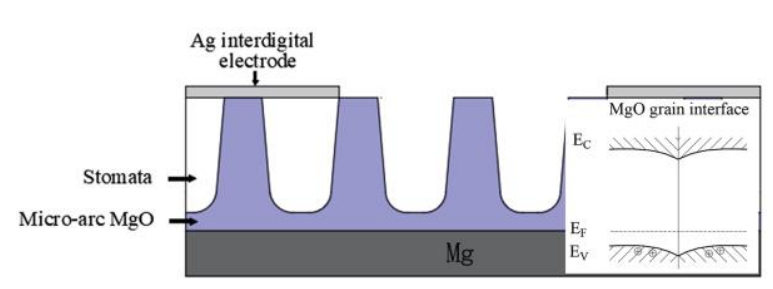

(a)

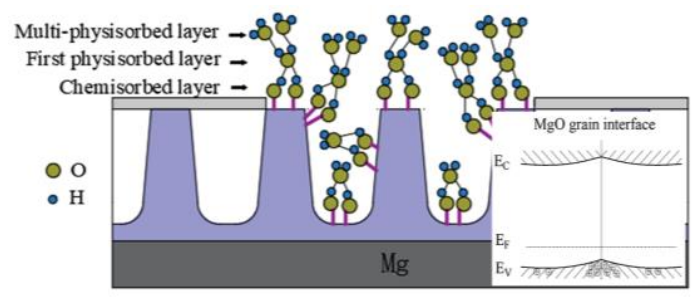

(b)

Figure 9. Schematic diagram of the mechanism of micro-arc $\mathrm{MgO}$ film surface (a) before water molecule adsorption and (b) after water molecule adsorption. The illustration in (a) is the surface energy state of the film before the adsorption of water molecules, and the illustration in $(\mathbf{b})$ is the surface energy state of the film after the adsorption of water molecules.

\section{Conclusions}

For the first time, we used MAO to prepare a $\mathrm{MgO}$ ceramic moisture-sensitive film with a large number of micropores appearing on the surface, and we used impedance and capacitance as the response signals. The experimental results showed that in the low humidity range (11.3-67\%RH) with impedance as the response signal, the average output was up to 150, with faster response (13 s) and recovery $(61 \mathrm{~s})$. Under the high humidity conditions (67-97.3\%), with capacitance as the response signal, the average output of the micro-arc MgO humidity sensor was as high as 120 . Based on the above experimental results, we can increase the humidity detection range of the sensing material by selecting an appropriate response signal for different humidity conditions, and then develop a humidity sensor with fast response and recovery, small hysteresis, and high response. 
Author Contributions: This work was formalized through the collaboration of all authors. M.P. conceived and designed the experiments; J.S. performed and completed the experiment as well as analyzed the data; J.L. wrote the original draft preparation; Z.S. and L.J. made the charts, reviews, and analysis; M.P. and J.L. funded the acquisition. All authors have read and agreed to the published version of the manuscript.

Funding: This work was supported by the Micro-nano Packaging and Testing and Operation Technology Laboratory of Soochow University.

Conflicts of Interest: The authors declare no conflict of interest.

\section{References}

1. Tételin, A.; Pellet, C.; Laville, C.; N'Kaoua, G. Fast response humidity sensors for a medical microsystem. Sens. Actuators B Chem. 2003, 91, 211-218. [CrossRef]

2. Rittersma, Z.M. Recent achievements in miniaturised humidity sensors-A review of transduction techniques. Sens. Actuators A Phys. 2002, 96, 196-210. [CrossRef]

3. Benabdellah, N.; Bourhaleb, M.; Nasri, M.; Benazzi, N.; Dahbi, S. Design of temperature and humidity sensors for an electronic nose used in rotten food. In Proceedings of the 2016 2nd International Conference on Electrical and Information Technologies (ICEIT), Piscataway, NJ, USA, 4-7 May 2016; pp. 505-509.

4. Lennon, J.A.; O'Brien, D.; Akkari, F. Fibre optic humidity sensors for the mushroom industry and for the curing of meats. In Proceedings of the Conference for Sensors, Measurement and Control, Tavistock, UK, 16-17 February 2000; Volume 1, p. 8.

5. Dubey, C.; Kumar, B. Organic humidity sensors with different materials and its application in environment monitoring. In Proceedings of the 2018 5th IEEE Uttar Pradesh Section International Conference on Electrical, Electronics and Computer Engineering (UPCON), Piscataway, NJ, USA, 2-4 November 2018; p. 6.

6. Leal-Junior, A.G.; Prado, A.; Frizera, A.; Pontes, M.J. Smartphone integrated polymer optical fiber humidity sensor: Towards a fully portable solution for healthcare. IEEE Sens. Lett. 2019, 3, 5000304. [CrossRef]

7. Yin, Y.-Y.; Xing, Y.; Li, M.-W.; Li, Y.-N.; Wang, J.-N.; Li, T.; Zhang, L.-X. A 3D pillared-layer cadmium (II) metal-organic framework for chemiresistive humidity sensing with high performance. Inorg. Chem. Commun. 2018, 97, 49-55. [CrossRef]

8. Juhasz, L.; Mizsei, J. Humidity sensor structures with thin film porous alumina for on-chip integration. Thin Solid Film. 2009, 517, 6198-6201. [CrossRef]

9. Mallick, S.; Ahmad, Z.; Touati, F.; Shakoor, R.A. Improvement of humidity sensing properties of $\mathrm{PVDF}^{-\mathrm{TiO}}{ }_{2}$ nanocomposite films using acetone etching. Sens. Actuators B-Chem. 2019, 288, 408-413. [CrossRef]

10. Zhang, D.; Wang, D.; Wang, D.; Wu, Z. Polypyrrole-Modified Tin Disulfide Nanoflower-Based Quartz Crystal Microbalance Sensor for Humidity Sensing. IEEE Sens. J. 2019, 19, 9166-9171. [CrossRef]

11. Arunachalam, S.; Izquierdo, R.; Nabki, F. Low-Hysteresis and Fast Response Time Humidity Sensors Using Suspended Functionalized Carbon Nanotubes. Sensors 2019, 19, 680. [CrossRef]

12. Yu, H.; Gao, S.; Cheng, X.; Wang, P.; Zhang, X.; Xu, Y.; Zhao, H.; Huo, L. Morphology controllable $\mathrm{Fe} 2 \mathrm{O} 3$ nanostructures derived from Fe-based metal-organic frameworks for enhanced humidity sensing performances. Sens. Actuators B Chem. 2019, 297, 126744. [CrossRef]

13. Dai, J.; Zhao, H.; Lin, X.; Liu, S.; Fei, T.; Zhang, T. Design strategy for ultrafast-response humidity sensors based on gel polymer electrolytes and application for detecting respiration. Sens. Actuators B Chem. 2020, 304, 127270. [CrossRef]

14. Wang, Q.; Pan, Y.Z.; Huang, S.S.; Ren, S.T.; Li, P.; Li, J.J. Resistive and capacitive response of nitrogen-doped $\mathrm{TiO}_{2}$ nanotubes film humidity sensor. Nanotechnology 2011, 22. [CrossRef]

15. Andika, R.; Aziz, F.; Ahmad, Z.; Doris, M.; Fauzia, V.; Bawazeer, T.M.; Alsenany, N.; Alsoufi, M.S.; Supangat, A. Organic nanostructure sensing layer developed by AAO template for the application in humidity sensors. J. Mater. Sci. Mater. Electron. 2019, 30, 2382-2388. [CrossRef]

16. Lu, Y.; Li, T.; Shang, X.; Wang, Y.; Cai, X. Research progress of micro-arc oxidation surface treatment of magnesium alloy. J. Biomed. Eng. 2016, 33, 1016-1019. [CrossRef]

17. Zhang, L.; Zhang, J.; Chen, C.-F.; Gu, Y. Advances in microarc oxidation coated AZ31 Mg alloys for biomedical applications. Corros. Sci. 2015, 91, 7-28. [CrossRef] 
18. Thirupathi, R.; Solleti, G.; Sreekanth, T.; Sadasivuni, K.K.; Rao, K.V. A Comparative Study of Chemically and Biologically Synthesized MgO Nanomaterial for Liquefied Petroleum Gas Detection. J. Electron. Mater. 2018, 47, 3468-3473. [CrossRef]

19. Kaur, S.; Singh, J.; Rawat, R.; Kumar, S.; Kaur, H.; Rao, K.V.; Rawat, M. A smart LPG sensor based on chemo-bio synthesized MgO nanostructure. J. Mater. Sci. Mater. Electron. 2018, 29, 11679-11687. [CrossRef]

20. Reddy, L.P.B.; Megha, R.; Chethan, B.; Prakash, H.G.R.; Ravikiran, Y.T.; Ramana, C.H.V.V.; Kim, D. Role of molybdenum trioxide in enhancing the humidity sensing performance of magnesium ferrite/molybdenum trioxide composite. Inorg. Chem. Commun. 2018, 98, 68-74. [CrossRef]

21. Lu, X.; Lei, L.; Shen, Y.; Li, Y.; Wang, L. Design of the Sensor Signal Display and Switching System for Nano Measuring Machine. Process Autom. Instrum. 2012, 33, 63-65.

22. Zhang, D.; Wang, M.; Zhang, W.; Li, Q. Flexible humidity sensing and portable applications based on MoSe2 nanoflowers/copper tungstate nanoparticles. Sens. Actuators B Chem. 2020, 304, 127234. [CrossRef]

23. Burman, D.; Choudhary, D.S.; Guha, P.K. ZnO/MoS 2 -Based Enhanced Humidity Sensor Prototype with Android App Interface for Mobile Platform. IEEE Sens. J. 2019, 19, 3993-3999. [CrossRef]

24. Aher, R.; Bhorde, A.; Nair, S.; Borate,H.; Pandharkar, S.; Naik, D.; Vairale, P.; Karpe, S.; Late, D.; Prasad, M.; et al. Solvothermal Growth of PbBi2Se4 Nano-Flowers: A Material for Humidity Sensor and Photodetector Applications. Phys. Status Solidi A Appl. Mater. Sci. 2019, 216. [CrossRef]

25. Zhu, P.; Liu, Y.; Fang, Z.; Kuang, Y.; Zhang, Y.; Peng, C.; Chen, G. Flexible and Highly Sensitive Humidity Sensor Based on Cellulose Nanofibers and Carbon Nanotube Composite Film. Langmuir 2019, 35, 4834-4842. [CrossRef] [PubMed]

26. Liu, H.; Wang, Q.; Sheng, W.J.; Wang, X.B.; Zhang, K.D.; Du, L.; Zhou, J. Humidity Sensors with Shielding Electrode Under Interdigitated Electrode. Sensors 2019, 19, 11. [CrossRef] [PubMed]

27. Zhao, Y.; Yang, B.; Liu, J. Effect of interdigital electrode gap on the performance of $\mathrm{SnO}_{2}$-modified $\mathrm{MoS}_{2}$ capacitive humidity sensor. Sens. Actuators B Chem. 2018, 271, 256-263. [CrossRef]

28. Luo, L.; Yuan, M.; Sun, H.; Peng, T.; Xie, T.; Chen, Q.; Chen, J. Effect of calcination temperature on the humidity sensitivity of $\mathrm{TiO}_{2}$ /graphene oxide nanocomposites. Mater. Sci. Semicond. Process. 2019, 89, 186-193. [CrossRef]

29. Zhang, H.; Yu, S.; Chen, C.; Zhang, J.; Liu, J.; Li, P. Effects on structure, surface oxygen defects and humidity performance of Au modified ZnO via hydrothermal method. Appl. Surf. Sci. 2019, 486, 482-489. [CrossRef]

30. Manjunatha, S.; Machappa, T.; Ravikiran, Y.T.; Chethan, B.; Revanasiddappa, M. Room temperature humidity sensing performance of polyaniline-holmium oxide composite. Appl. Phys. A 2019, 125, 361. [CrossRef]

31. Rahim, I.; Shah, M.; Khan, A.; Luo, J.; Zhong, A.; Li, M.; Ahmed, R.; Li, H.; Wei, Q.; Fu, Y. Capacitive and resistive response of humidity sensors based on graphene decorated by PMMA and silver nanoparticles. Sens. Actuators B Chem. 2018, 267, 42-50. [CrossRef]

32. Jiang, W.F.; Jia, M.; Wang, Y.S.; Li, L.Y.; Li, X.J. Accelerated resistive humidity sensing properties of silicon nanoporous pillar array. Thin Solid Film. 2009, 517, 2994-2996. [CrossRef]

33. Sharma, K.; Islam, S.S. Optimization of porous anodic alumina nanostructure for ultra high sensitive humidity sensor. Sens. Actuators B Chem. 2016, 237, 443-451. [CrossRef]

34. Reddy, L.P.B.; Megha, R.; Prakash, H.G.R.; Ravikiran, Y.T.; Ramana, C.H.V.V.; Kumari, S.C.V.; Kim, D. Copper ferrite-yttrium oxide (CFYO) nanocomposite as remarkable humidity sensor. Inorg. Chem. Commun. 2019, 99, 180-188. [CrossRef]

35. Pradeep, N.; Venkatachalaiah, C.; Venkatraman, U.; Santhosh, C.; Bhatnagar, A.; Jeong, S.K.; Grace, A.N. Magnesium oxide nanocubes deposited on an overhead projector sheet: Synthesis and resistivity-based hydrogen sensing capability. Microchim. Acta 2017, 184, 3349-3355. [CrossRef]

36. Hu, G.F.; Zhou, R.R.; Yu, R.M.; Dong, L.; Pan, C.F.; Wang, Z.L. Piezotronic effect enhanced Schottky-contact ZnO micro/nanowire humidity sensors. Nano Res. 2014, 7, 1083-1091. [CrossRef]

37. Herrán, J.; Fernández, I.; Tena-Zaera, R.; Ochoteco, E.; Cabañero, G.; Grande, H. Schottky diodes based on electrodeposited $\mathrm{ZnO}$ nanorod arrays for humidity sensing at room temperature. Sens. Actuators B Chem. 2012, 174, 274-278. [CrossRef]

38. Anderson, J.H.; Parks, G.A. Electrical conductivity of silica gel in the presence of adsorbed water. J. Phys. Chem. 1968, 72, 3662-3668. [CrossRef] 
39. Chen, S.W.; Khor, O.K.; Liao, M.W.; Chung, C.K. Sensitivity evolution and enhancement mechanism of porous anodic aluminum oxide humidity sensor using magnetic field. Sens. Actuators B Chem. 2014, 199, 384-388. [CrossRef]

40. Dickey, E.C.; Varghese, O.K.; Ong, K.G.; Gong, D.W.; Paulose, M.; Grimes, C.A. Room temperature ammonia and humidity sensing using highly ordered nanoporous alumina films. Sensors 2002, 2, 91-110. [CrossRef]

41. Zhen, Y.; Wang, M.; Wang, S.; Xue, Q. Humidity sensitive properties of amorphous (K,Na)NbO3 lead free thin films. Ceram. Int. 2014, 40, 10263-10267. [CrossRef]

(C) 2020 by the authors. Licensee MDPI, Basel, Switzerland. This article is an open access article distributed under the terms and conditions of the Creative Commons Attribution (CC BY) license (http://creativecommons.org/licenses/by/4.0/). 